\title{
Reliable and rapid smooth extubation after Ketofol for induction of general anesthesia in Laparoscopic Drilling of polycystic ovary: A randomized controlled trial
}

\author{
Atef Mohamed Sayed Mahmoud \\ Fayoum University Faculty of Medicine \\ Joseph Makram Botros ( $\sim$ dr_jo27@yahoo.com ) \\ Fayoum University Faculty of Medicine \\ Safaa Gaber Ragab
}

Fayoum University Faculty of Medicine

\section{Research article}

Keywords: ketofol, airway response, hemodynamics, smoothness of extubation, general anesthesia

Posted Date: May 21st, 2020

DOl: https://doi.org/10.21203/rs.3.rs-29085/v1

License: (c) (1) This work is licensed under a Creative Commons Attribution 4.0 International License.

Read Full License 


\section{Abstract \\ Background}

the outcome of ketofol on the hemodynamics and the airway response during induction of general anesthesia has been studied before. Its effect on smoothness of extubation has not been studied before. So, we aimed to assess the effect of ketofol on the smoothness of extubation and compare it with propofol only for induction of general anesthesia.

\section{Methods}

This double-blind, randomized, and controlled study was conducted on one hundred and six American Society of Anesthesiologists Physical status "ASA PS" class I and II female patients aged 18-40 years old and scheduled for laparoscopic drilling for polycystic ovary disease under general anesthesia. The patients were assigned into one of two groups (53) patients each; group KP = ketofol and group $\mathrm{P}=$ propofol.

\section{Results}

There was good sedation score during suction and extubation in the ketofol group. Airway response and smoothness of extubation were better in the ketofol group better than the propofol group.

\section{Conclusion}

Ketofol as an induction anesthetic agent was effective in attenuating the airway response during extubation more than profofol only.

\section{Trial registration:}

This trial was retrospectively registered at the Clinical Trial.gov with the Identification Number: NCT04365686.

\section{Background}

Tracheal extubation is a critical and stressful moment during general anesthesia at which many hazardous and unwanted hemodynamics and airway responses may occur such as tachycardia, hypertension, dysrhythmias, coughing, laryngospasm, and bronchospasm ${ }^{(1,2)}$.

These hazardous responses are ought to the sudden release of catecholamines during tracheal extubation ${ }^{(3)}$ 
Many mediactions have been studied to reduce the stress response during extubation aiming for the achievement of a state of smooth extubation such as including intravenous lignocaine, short acting opoids as fentanyl and remifentanyl, esmolol, endotracheal local anesthetic instillation and dexmeditomedine $e^{(4-9)}$

Propofol (2, 6-diisopropylphenol) is a sedative and hypnotic drug with antiemetic property used for induction and maintenance of general anesthesia and in the intensive care units (ICU) for sedation. It produces its effect by facilitation of inhibitory neurotransmission mediated by GABA (Gama Amino Butyric Acid) depression (10-12)

Ketamine is a phencyclidine derivative used for induction of general anesthesia. It has favorable analgesic and amnestic properties but increases sympathetic activity, nausea, vomiting, and undesirable psychomimetic disorders. ${ }^{(13,14)}$

Ketofol (ketamine-propofol mixture) as an induction agent drug and its effect on hemodynamics has been studied previously. $(15,16)$ Its effect on the airway responses during induction of anesthesia was studied by Aberra B et al. (17)

We hypothesized that giving ketofol as an induction agent getting the beneficial effects of both medications would favorably affect both the hemodynamics and the airway response during extubation. The aim of this study was to compare the effect of injecting a single dose of ketofol versus propofol on the smoothness of extubation as regards the airway response and the hemodynamics when given for the induction of general anesthesia in laparoscopic drilling of polycystic ovary disease.

\section{Methods}

Following ethical committee approval and research is coded (R83) of Anesthesia department, Fayoum University and obtaining a written informed consent, this study was conducted on one hundred and six American Society of Anesthesiologists Physical Status "ASA PS" class I and II female patients aged above 18 years old up to 40 years old and scheduled for laparoscopic drilling for polycystic ovary under general anesthesia. This trial protocol was registered at the Clinical Trial.gov with the Identification Number: NCT04365686. This study was conducted in El Fayoum University Hospitals and took 12 months between April 2019 and April 2020. Patients suffering from cardiac, hepatic, renal diseases, history of epilepsy were excluded from this study. The patients were randomly allocated by a computergenerated table into one of two study groups. The randomization sequence was concealed in opaque sealed envelopes. The envelopes were opened by the study investigators just after recruitments and admission to the operation room. Only assessors and data collectors were blinded to the group's allocations. Our study adheres to CONSORT guidelines.

The two study groups of this randomized, double-blind and parallel clinical trial are: Group K (Ketofol group): includes fifty three female patients who received propofol $(1 \mathrm{mg} / \mathrm{kg})$ plus ketamine $(0.5 \mathrm{mg} / \mathrm{kg})$ 
at induction of general anesthesia and Group P (propofol group): includes fifty three female patients who received propofol $(2 \mathrm{mg} / \mathrm{kg})$ only at induction of general anesthesia.

After securing an intravenous access by a $20 \mathrm{~g}$ i.v. cannula, intravenous premedication (midazolam $2 \mathrm{mg}$ and $4 \mathrm{mg}$ ondansetron) was administered to all patients. Standard ASA monitoring (5-lead ECG, noninvasive blood pressure (NIBP), and pulse oximetry) was applied to all the patients for recording of heart rate (HR), NIBP and oxygen saturation by a mutli-parameter monitor. Induction of general anesthesia was achieved as follows: in Group K (Ketofol group), fifty three female patients received propofol $(1 \mathrm{mg} / \mathrm{kg})$ plus ketamine $(0.5 \mathrm{mg} / \mathrm{kg})$ at induction of general anesthesia while in Group P (Propofol group), fifty three female patients received propofol $(2 \mathrm{mg} / \mathrm{kg})$ only at induction of general anesthesia.

Patients in both groups received intravenous fentanyl $2 \mu \mathrm{g} \backslash \mathrm{kg}$, and atracurium $0.5 \mathrm{mg} \backslash \mathrm{kg}$. After tracheal intubation, general anesthesia was maintained by isoflurane 1.5\% in $2 \mathrm{~L} \backslash \mathrm{min}$ oxygen-air mixture $50 \%: 50 \%$ and atracurium $0.1 \mathrm{mg} \backslash \mathrm{kg}$ every 30 minutes, if needed. At the end of surgery, inhalational anesthesia was stopped and reversal of the neuromuscular blockade was done by intravenous neostigmine $0.05 \mathrm{mg} \backslash \mathrm{kg}$ and atropine $0.01 \mathrm{mg} \backslash \mathrm{kg}$.

Hemodynamics [HR and mean arterial blood pressure (MAP)] were assessed at 5 minutes interval from the time of reversal of muscle relaxant up to 30 minutes after extubation. The level of sedation during suction and extubation was assessed using observer assessment sedation score (Table: 1) and the airway response under direct laryngoscopy to suction was noted by five point scale (Table 2). ${ }^{(18)}$ After 5 minute interval the level of sedation and smoothness of extubation was noted by four point scale (Table: 3). ${ }^{(18)}$

Table 1

Observer assessment sedation score.

\begin{tabular}{|ll|}
\hline Observation & Score \\
\hline Responds readily to name spoken in normal tone & 5 \\
\hline Lethargic response to name spoken in normal tone & 4 \\
\hline Responds only after name is called loudly and \or repeatedly & 3 \\
\hline Responds only after mild podding or shaking & 2 \\
\hline Dose not responds to mild podding or shaking & 1 \\
\hline
\end{tabular}


Table 2

Grading of air way reflexes.

\begin{tabular}{|ll|}
\hline Grade & Description \\
\hline 1 & Excellent (breathing well, no response to laryngoscopy\& suctioning) \\
\hline 2 & Good (breathing well, minimal grimacing response to laryngoscope\& suctioning) \\
\hline 3 & Satisfactory (breathing well coughing attempt to laryngoscopy\& suctioning) \\
\hline 4 & Poor (breathing well, coughing on tube laryngoscopy) \\
\hline 5 & Very poor (breathing well, coughing on tube laryngoscopy) \\
\hline
\end{tabular}

Table 3

Smoothness of extubation.

\begin{tabular}{|ll|}
\hline Grade & Description \\
\hline 1 & No coughing on endotracheal tube \\
\hline 2 & Coughing on the tube \\
\hline 3 & Vomiting \\
\hline 4 & Laryngospasm \\
\hline
\end{tabular}

Table 4

Demographic data .

\begin{tabular}{|c|c|c|c|}
\hline Parameters & $\begin{array}{l}\text { Group K (Ketofol), N= } 53 \\
\text { Mean } \pm \text { SD }\end{array}$ & Group P (Propofol), N = 53 Mean \pm SD & $P$-Value* \\
\hline Age (years) & $27.68 \pm 3.67$ & $26.49 \pm 3.06$ & 0.073 \\
\hline Height (cm) & $164.13 \pm 5.20$ & $166.25 \pm 5.05$ & $0.036^{\star *}$ \\
\hline Weight (kg) & $74.42 \pm 10.19$ & $73.36 \pm 7.92$ & 0.552 \\
\hline BMI & $27.70 \pm 4.18$ & $26.56 \pm 2.80$ & 0.103 \\
\hline
\end{tabular}


Table 5

Hemodynamic variables at different study time points.

\begin{tabular}{|c|c|c|c|c|}
\hline Group & $\begin{array}{l}\text { Ketofol } \\
\text { group } \\
\text { (Ketofol), N = } \\
53\end{array}$ & $\begin{array}{l}\text { Propofol } \\
\text { group } \\
\text { (Propofol), N } \\
=53\end{array}$ & $\begin{array}{l}P \\
\text { value* }\end{array}$ & $\begin{array}{l}95 \% \mathrm{Cl} \text { of the } \\
\text { difference }\end{array}$ \\
\hline & Mean \pm SD & Mean \pm SD & & \\
\hline $\begin{array}{l}\text { MAP at }(5) \text { min before } \\
\text { extubation. }\end{array}$ & $\begin{array}{l}107.19 \pm \\
10.34\end{array}$ & $115.64 \pm 11.01$ & $<.001^{\star *}$ & $-12.6,-3.4$ \\
\hline MAP at the time of extubation. & $\begin{array}{l}107.49 \pm \\
12.52\end{array}$ & $112.96 \pm 11.10$ & $0.019 * *$ & $-10.0,-0.9$ \\
\hline $\begin{array}{l}\text { MAP at (5) min after } \\
\text { extubation. }\end{array}$ & $\begin{array}{l}103.04 \pm \\
13.00\end{array}$ & $104.36 \pm 7.86$ & 0.528 & $-5.4,2.8$ \\
\hline $\begin{array}{l}\text { MAP at }(10) \text { min after } \\
\text { extubation. }\end{array}$ & $94.92 \pm 5.59$ & $97.66 \pm 4.61$ & $0.007 * \star$ & $-4.7,-0.8$ \\
\hline $\begin{array}{l}\text { MAP at (15) min after } \\
\text { extubation. }\end{array}$ & $90.43 \pm 5.49$ & $93.75 \pm 5.28$ & $0.002^{\star \star}$ & $-6.7,-1.8$ \\
\hline $\begin{array}{l}\text { MAP at }(20) \text { min after } \\
\text { extubation. }\end{array}$ & $83.30 \pm 5.99$ & $90.15 \pm 3.86$ & $<.001^{\star *}$ & $-8.8,-4.9$ \\
\hline $\begin{array}{l}\mathrm{HR} / \min \text { at }(5) \mathrm{min} \text { before } \\
\text { extubation. }\end{array}$ & $85.47 \pm 13.93$ & $104.55 \pm 10.83$ & $<.001^{\star \star}$ & $-23.8,-12.4$ \\
\hline $\begin{array}{l}\mathrm{HR} / \min \text { at the time of } \\
\text { extubation. }\end{array}$ & $87.75 \pm 1.22$ & $103.72 \pm 6.48$ & $\dot{0.001 * \star}$ & $-19.5,-12.4$ \\
\hline $\begin{array}{l}\text { HR/min at (5) min after } \\
\text { extubation. }\end{array}$ & $82.26 \pm 8.01$ & $97.34 \pm 7.03$ & $<.001^{\star \star}$ & $-118,-12.2$ \\
\hline $\begin{array}{l}\text { HR/min at }(10) \text { min after } \\
\text { extubation. }\end{array}$ & $79.25 \pm 7.36$ & $92.81 \pm 7.00$ & $<0.001^{\star *}$ & $-16.3,-10.8$ \\
\hline $\begin{array}{l}\mathrm{HR} / \mathrm{min} \text { at (15) min after } \\
\text { extubation. }\end{array}$ & $75.36 \pm 6.51$ & $90.23 \pm 6.08$ & $<.001^{\star \star}$ & $-17.3 .-12.4$ \\
\hline $\begin{array}{l}\mathrm{HR} / \min \text { at }(20) \text { min after } \\
\text { extubation. }\end{array}$ & $72.98 \pm 5.40$ & $86.38 \pm 5.07$ & $<.001^{\star \star}$ & $-15.4,-11.4$ \\
\hline
\end{tabular}


Table 6

comparing outcome variables between the two groups.

\begin{tabular}{|c|c|c|c|c|c|c|}
\hline & & & $\begin{array}{l}\text { Ketofol } \\
\text { (K group) }\end{array}$ & $\begin{array}{l}\text { Propofol } \\
\text { (P group) }\end{array}$ & $\begin{array}{l}\text { P-value for Chi } \\
\text { Square test }\end{array}$ & $\begin{array}{l}\text { Somers' D value } \\
\text { (measure of trend) }\end{array}$ \\
\hline \multirow[t]{3}{*}{$\begin{array}{l}\text { Level of sedation } \\
\text { during suction }\end{array}$} & 1 & $\begin{array}{l}\mathrm{N} \\
(\%)\end{array}$ & $44(83 \%)$ & 10(18.9) & $<0.001^{\star}$ & 0.675 \\
\hline & 2 & $\begin{array}{l}\mathrm{N} \\
(\%)\end{array}$ & $7(13.2 \%)$ & $23(43.4)$ & & \\
\hline & 3 & $\begin{array}{l}\mathrm{N} \\
(\%)\end{array}$ & $2(3.8 \%)$ & $20(37.7)$ & & \\
\hline \multirow[t]{4}{*}{ Airway reflex } & 2 & $\begin{array}{l}\mathrm{N} \\
(\%)\end{array}$ & $11(20.8 \%)$ & $2(3.8 \%)$ & $<0.001^{\star}$ & 0.553 \\
\hline & 3 & $\begin{array}{l}\mathrm{N} \\
(\%)\end{array}$ & $33(62.3 \%)$ & $12(22.6 \%)$ & & \\
\hline & 4 & $\begin{array}{l}\mathrm{N} \\
(\%)\end{array}$ & $5(9.4 \%)$ & $33(62.3 \%)$ & & \\
\hline & 5 & $\begin{array}{l}\mathrm{N} \\
(\%)\end{array}$ & $4(7.5 \%)$ & $6(11.3 \%)$ & & \\
\hline \multirow[t]{3}{*}{$\begin{array}{l}\text { Level of sedation at } \\
\text { extubation }\end{array}$} & 2 & $\begin{array}{l}\mathrm{N} \\
(\%)\end{array}$ & $7(13.2 \%)$ & 0 & $<0.001$ * & 1 \\
\hline & 3 & $\begin{array}{l}\mathrm{N} \\
(\%)\end{array}$ & $\begin{array}{l}46 \\
(86.8 \%)\end{array}$ & 0 & & \\
\hline & 5 & $\begin{array}{l}\mathrm{N} \\
(\%)\end{array}$ & 0 & $53(100 \%)$ & & \\
\hline \multirow[t]{4}{*}{$\begin{array}{l}\text { Smoothness of } \\
\text { extubation }\end{array}$} & 1 & $\begin{array}{l}\mathrm{N} \\
(\%)\end{array}$ & $53(100 \%)$ & 0 & $<0.001$ * & 1 \\
\hline & 2 & $\begin{array}{l}\mathrm{N} \\
(\%)\end{array}$ & 0 & $\begin{array}{l}20 \\
(37.7 \%)\end{array}$ & & \\
\hline & 3 & $\begin{array}{l}\mathrm{N} \\
(\%)\end{array}$ & 0 & $\begin{array}{l}30 \\
(56.6 \%)\end{array}$ & & \\
\hline & 4 & $\begin{array}{l}\mathrm{N} \\
(\%)\end{array}$ & 0 & $3(5.7 \%)$ & & \\
\hline
\end{tabular}

Our primary outcome was assessment of smoothness of extubation while, our secondary outcomes were assessment of airway response to laryngoscopy and suction, sedation score, and hemodynamics as mentioned before.

\section{Sample size calculation}


Based on our pilot study, that was done on thirty patients who were randomly allocated by blind envelope methods into three groups ten patients each. These patients were not included in the final study. Sample size was calculated ( $^{*}$ power version 3.0.10). Minimal sample size was calculated as 48 patients in both groups needed to get the power level of 0.80 , alpha level of 0.05 (two tailed), and effect size of 0.58 for grading of smoothness of extubation grade 1 (mean \pm SD) in the study group and in the control group only is $(1.5 \pm 0.8)$ and $(2.0 \pm 1.2)$ respectively. Based on the results of the pilot study to overcome problem of loss of follow up, calculated sample size was increased by $10 \%$ to reach 53 in each group.

\section{Statistical analysis}

Statistical analysis was done SPSS for windows software version 23. Descriptive statistics was done for categorical variables and presented as numbers and percentages. While for numerical data, descriptive statistics were done the mean and the standard deviation being normally distributed. Independent t test was used to compare numeric variables in the two groups being either normally distributed data or based on the central limit theorem. Chi-Square test to analyze the difference in the extubation quality, the sedation score and the adverse events. $P$ value $<0.05$ was considered as statistically significant.

\section{Results}

A total of 106 patients participated in this study. They were randomized into the $\mathrm{K}$ group (53 patients) and the $\mathrm{P}$ group (53 patients). There were no statistically significant differences between the two study groups as regard the demographic data except for the height which is clinically insignificant (Table: 4).

Hemodynamic parameters (MAP and HR) 5 min before extubation, at extubation, and every 5 min later till 20 minutes post-extubation are detailed in (Table:5).

The MAP was significantly higher in the propofol group than in the ketofol group at all the readings except at 5 min after extubation where the difference was non-significant (Table: 5).

HR was lower in the ketofol group than in the propofol group at all reading times and that difference was statistically significant (Table: 5).

The grade of smoothness of extubation, our primary outcome, was 1 in all cases of the kotofol group and the grade was 2 to 4 for the cases of the propofol group. The relationship is highly significant and the Somers' $\mathrm{D}$ value $=1$ meaning that there is a perfect trend association (Table: 6 ) and (Figure: 1 ).

The level of sedation during suction was 1 in $83 \%$ of the ketofol cases with lower numbers at levels 2 and 3. While in the propofol group, it was at level of $1 \mathrm{in} 19 \%$ of the cases whereas, the rest of the cases were at levels of 2 and 3. This relationship is highly significant and the Somers' D value $=0.67$ meaning that there is a strong trend association (Table: 6).

The grade of airway reflex was 2 in 11 cases $(20.8 \%)$ and 3 in 33 cases $(62.3 \%)$ of the kotofol cases with lower numbers at grades 4 and 5 . While in the propofol group, 12 cases $(22.6 \%)$ of the cases were at 
grade 2 and 33 cases (62.3\%) at grade 4 . Also, this relationship is highly significant and the Somers' D value $=0.55$ meaning that there is a strong trend association (Table: 6 ).

The level of sedation at extubation was 5 in all cases of the propofol group whereas; it was at the level of 2 and 3 for the cases of ketofol group. The relationship is highly significant and the Somers' D value $=1$ meaning that there is a perfect trend association (Table: 6).

\section{Discussion}

Stress response during extubation is an unwanted and unpredictable response that makes anesthesiologists vigilant and attentive for minimizing its effect on hemodynamics and airway reflexes.

In our study we compared the effect of injecting a ketofol compared to propofol at induction of general anesthesia on the smoothness of extubation as regards airway response and hemodynamics in laparoscopic drilling of polycystic ovary disease.

Aboeldahab et al studied the effect of ketofol compared to its two constituents as an induction agent in 60 patients undergoing hernia repair under general anesthesia. ${ }^{(15)}$ They examined its effect as an induction agent clinically by assessing the hemodynamics and by using the BIS index where, 20 of them were given ketofol, 20 were given propofol and the last 20 were given ketamine during induction of anesthesia. During extubation HR in ketofol group $(81.65 \pm 2.60)$ was lower than in the propofol group $(81.73 \pm 3.93)$ but, with no statistical significance and MAP in the ketofol group ( $83.90 \pm 3.30)$ was lower than in the propofol group $(85.66 \pm 3.43)$ with also, no statistical significance. This might be due to the lengthy procedure in their study and /or due to the small sample size of the groups. Our results came in agreement with Aboeldahab et al, as ketofol was associated with more stable hemodynamics than propofol during extubation. We attributed this to the good level of sedation of ketofol during suction and extubation due to the additive sedative effect of both ketamine and propofol.

We cocluded that the effect of ketofol on HR was more important and more significant in stabilizing the heamodynamics than its effect on MAP when compared to popofol.

On the other hands, Jalili et al, who compared the effect of propofol and ketofol on emergence delerium in 87 ASA I and II children aged from 3-12 years and underwent adenotonsillectomy, reported no statistically significant difference between the two groups regarding HR in the recovery room at 0,10 , and 20 minutes postoperatively. ${ }^{(19)}$

The smoothness of extubation without coughing, laryngospasm and vomiting on the tube was examined in both groups and it was in favor of ketofol group.

Recently, Aberra et al, in a study done on 120 pediatric patients aged from 2 to 15 years undergoing elective ophthalmic surgical procedures under general anesthesia using laryngeal mask airway (LMA) to compare the ketamine-propofol mixture (ketofol) with propofol on the ease of laryngeal mask airway 
insertion conditions and hemodynamic effects during induction of general anesthesia, found that 54 patients in the ketofol group compared to 52 in the propofol group developed no cough, 6 patients in ketofol group compared to 7 patients in propofol group developed slight cough (coughing which can occur immediately after LMA and subside by itself) and 1 patient in propofol group developed gross cough (coughing which needs deepening of anesthesia to be relieved) with no significant difference between them. ${ }^{(17)}$

The sedation scores during suction and extubation were significantly lower in the ketofol group compared to the propofol group. We attributed this good level of sedation during suction and extubation to the analgesic effect of ketamine.

In our study, we reported that the ketofol group showed better airway response than the propofol group. One of the most unwanted adverse effects of stress response on air way is cough. Kim and Bishopreported an incidence rate of $75 \%$ of cough in patients during emergence and extubation. ${ }^{(20)}$ Hypertension, tachycardia, myocardial ischemia, and bronchospasm are adverse effects related to cough.

In our study, the majority of patients in the ketofol group [44 patients (83.1\%)] developed better airway reflexes (grade 2,3) during suction better than the majority of patients in the propofol group [39 patients (73.6\%) ] developed higher degree of airway reflexes (grade 4 or 5). From all of the previous, we gave another explanation for the better hemodynamic stability during extubation in the ketofol group.

Aberra et al reported that no patient in the ketofol group developed laryngospasm while, 2 patients in the propofol group developed partial laryngospasm with no statistical significance. They concluded that Ketofol provided equivalent laryngeal mask airway insertion conditions and it can be used as an alternative propofol for LMA insertion. ${ }^{(17)}$

\section{Conclusion}

Giving ketofol during induction of general anesthesia in laparoscopic drilling of polycystic ovary provided a good sedation score during suction and extubation, better airway response during suction, smoothness of tracheal extubation and more stable hemodynamics than propofol only group.

\section{Limitation}

We did this study in a relatively short surgical procedure that could be a limitation of our study.

\section{Abbreviations}

\section{ASA PS}

Society of Anesthesiologists Physical Status.

HR

Heart Rate. 
GABA

Gama Amino Butyric Acid.

ICU

Intensive Care Unit.

LMA

Laryngeal Mask Airway.

MAP

Mean Arterial Pressure.

NIBP

Non Invasive Blood Pressure.

\section{Declarations}

- Ethics approval and consent to participate:

- Fayoum University Ethical Committee approval.

\section{- Availability of data and material:}

- All data are available.

- Competing interests:

- No competing interest.

\section{- Funding:}

Fayoum University Hospital resources and our own resources.

\section{- Authors Contribution:}

All authors contributed equally in this work. AM invited the idea, shared in the statistical analysis and shared in writing the manuscript. SG shared in writing the manuscript and language editing. JB edited shared in writing, revised the manuscript, language editing and the corresponding author. All authors red and approved the manuscript.

\section{- Acknowledgements:}

- our families. 


\section{References}

1. - Cranfield KA, Bromley LM. Minimum alveolar concentration of desflurane for tracheal extubation in deeply anaesthetized, unpremedicated children. Br J Anaesth. 1997;78:370-1.

2. -Hartely M, Vaughan RS. Proplems with tracheal extubation. Br J Anaesthesia. 1993;71:561-8.

3. - Lowrie A, Johnston PL, Fell D, Robinson SL. Cardiovascular and plasma catecholamine responses at tracheal extubation. Br J Anaesth. 1992;68:261-3.

4. - Gefke K, Andersen LW, Friesel E. Lidocaine given intravenously as a suppressant of cough and laryngospasm in connection with extubation after tonsillectomy. Acta Anaesthesiol Scand. 1983;27:111-2.

5. - Nishina K, Mikawa K, Maekawa N, Obara H. Fentanyl attenuates cardiovascular responses to tracheal extubation. Acta Anaesthesiol Scand. 1995;39:85-9.

6. - Aouad MT, Al-Alami AA, Nasr VG, Souki FG, Zbeidy RA, Siddik-Sayyid SM. The effect of low-dose remifentanil on responses to the endotracheal tube during emergence from general anesthesia. Anesth Analg. 2009;108:1157-60.

7. - Lim SH, Chin NM, Tai HY, Wong M, Lin TK. Prophylactic esmolol infusion for the control of cardiovascular responses to extubation after intracranial surgery. Ann Acad Med Singapore. 2000;29:447-51.

8. - Jee D, Park SY. Lidocaine sprayed down the endotracheal tube attenuates the airway-circulatory reflexes by local anesthesia during emergence and extubation. Anesth Analg. 2003;96:293-7.

9. - Jain D, Khan R, Maroof M. Effect of dexmeditomidine on stress response to extubation. Internet J Anaesthesiol. 2008;21:21-2.

10. Hug CC Jr, McLeskey CH, Nahrwold ML, Roizen MF, Stanley TH, Thisted RA, et al. Hemodynamic effects of propofol: data from over 25,000 patients. Anesth Analg. 1993;77(4):21-9.

11. Bassett KE, Anderson JL, et al. Propofol for procedural sedation in children in the emergency department. Ann Emerg Med. 2003;42:773-82.

12. Arora S. Combining ketamine and propofol ("ketofol") for emergency department procedural sedation and analgesia: a review. West J Emerg Med. 2008;9(1):20.

13. Strayer RJ, Nelson LS. Adverse events associated with ketamine for procedural sedation in adults. Am J Emerg Med. 2008;26:985-1028.

14. Morgan GE, Mikhail MS, Murray MJ. Nonvolatile anesthetic agents. Clin Anesthesiology 2002;8:15177 , 3rd ed.

15. Aboeldahab H, Samir R, Hosny H, Omar A. Comparative study between propof, ketamine and their combination (ketofol) as an induction agent. Egyptian Journal of Anaesthesia. 2011;27:145-50.

16. - ELZayyat NS, Hassan AR, ELSakka Al, Saad AH. Ketamine/propofol (ketofol) versus propofol/fentanyl for induction of general anesthesia in parturients with rheumatic valvular lesions undergoing elective cesarean section. The Egyptian Journal of Cardiothoracic Anesthesia. 2013;7:79-84. 
17. - Aberra B, Aregawi A, Teklay G, Tasew H. Effect of ketofol versus propofol as an induction agent on ease of laryngeal mask airway insertion conditions and hemodynamic stability in pediatrics: an observational prospective cohort study. BMC Anesthesiol. 2019;19:41.

18. -Rani P, Hemanth Kumar VR, Ravishankar M, Sivashanmugam T, Sripria R, Trilogasundary M. Rapid and reliable smooth extubation-comparison of fentanyl with dexmedetomidine: A randomized, double blind clinical trial. Anesth essays Res. 2016;10(3):597-601.

19. - Jalili S, Esmaeeili A, Kamali K, Rashtchi V. Comparison of effects of propofol and ketofol (KetaminePropofol mixture (on emergence agitation in children undergoing tonsillectomy. Afri Health Sci. 2019;19(1):1736-44.

20. -kim ES, Bishop MJ. Cough during emergence from isoflurane anesthesia. Anesth Analg. 1998;87:1170-4.

\section{Figures}

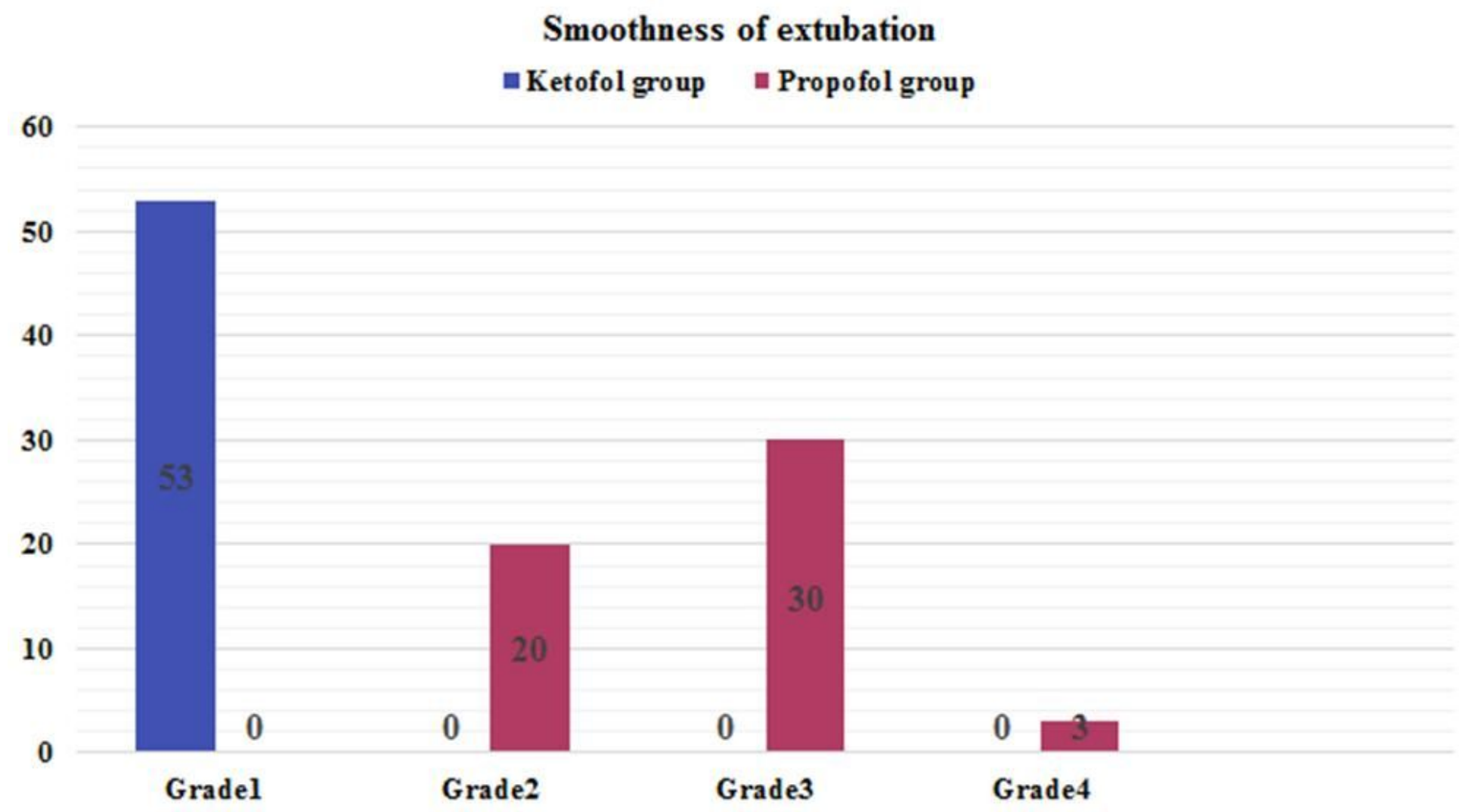

Figure 1

comparing the smoothness of extubation between the two groups

\section{Supplementary Files}

This is a list of supplementary files associated with this preprint. Click to download. 
- CONSORT2010Checklist12.doc

Page 14/14 